\title{
The social interaction role of song in song sparrows: implications for signal design
}

\author{
John M. Burt \& Michael D. Beecher \\ University of Washington
}

\begin{abstract}
Many territorial songbirds use singing as an interactive social signal to reduce inter-neighbor aggression. Communication theory predicts that territorial songbirds may use repertoires of signals to indicate graded levels of aggressive motivation. This theory is supported in song sparrows, a species that uses several different song-based signals such as song-type matching to escalate or de-escalate aggression during counter-singing interactions. However, birds cannot type match if they do not share the song type their rival is singing, raising the question of how they might signal aggression instead. We present evidence for two alternative signaling strategies that non-sharing neighbors could use to communicate aggressive motivation. In the first case, a bird may 'similarity match' a rival's song by singing the most similar song in his repertoire, even if he cannot type match. Another solution would be for neighbors to agree to treat specific pairs of non-similar types as matches by convention. The conventional match is potentially a new class of signal that territorial neighbors may use along with type and similarity matching to maintain a repertoire of aggressive motivation signals.
\end{abstract}

Keywords: song sparrow, bird song, animal communication, song matching, conventional matching.

Passerine songbirds (order Passeriformes, suborder oscines) are well known for their elaborate and complex song, which in most species is used as a long distance signal. Song is thought to function as a dual purpose signal intended to attract mates and/or as a keep-out signal to repel potential territorial rivals (Catchpole \& Slater, 1995). Although the female attraction role of bird song is important, this article will focus on the territorial role of song communication. That territorial defenders actively patrol their borders, and sing from posts at their territory boundaries, suggests that the songs serve as an acoustic ownership marker. Experimental evidence supports the keep-out role as well: when a singer is prevented from singing through surgical devocalization, other birds quickly invade and defend the space as if the silent owner does not exist (McDonald, 1989). Similarly, if a bird is removed from his territory a playback speaker broadcasting his songs will delay intruders for some time (review in Nowicki et al., 1998).

The research reviewed in this article and its preparation was supported by grants from the National Science Foundation. We thank Çaglar Akçay, who provided many hours of assistance analyzing song sparrow song interactions. Correspondence concerning the article should be addressed to John M. Burt, Department of Psychology, University of Washington, Seattle, Washington 98195. E-mail: quill@u.washington.edu
However, it is also apparent that song has territorial functions besides keep-out. Many studies have found that territorial birds use their songs to counter-sing with familiar established neighbors, and the interactive nature of territorial counter-singing, and its frequent use in contexts that do not involve a threat of takeover, suggest that song serves a social interaction function in addition to deterrence (Bradbury \& Vehrencamp, 1998). The evidence suggests that territorial singers (mostly neighbors) use a variety of different song signals to indicate differing levels of aggressive motivation or intention. Furthermore, observations of singing in songbird neighborhoods reveal that the interactive communication is usually an ongoing process that lasts throughout the breeding season, and that birds may use direct interaction as well as eavesdropping on other interactions to continually adjust their assessment of the status of their neighbors. For example, recent field experiments on songbirds have shown that males make decisions concerning whom to challenge and females make decisions concerning whom to mate with based on information acquired by eavesdropping on singing interactions (Naguib \& Todt, 1997; Otter et al., 1999; Mennill et al., 2002). In the species studied to date, song overlapping, song-type matching, frequency matching, and/or song leading seem to be some of the critical cues that indicate relative status between two singers (Mennill \& Ratcliffe, 
2004; Peake et al., 2005; Kunc et al., 2006).

Although the social function of song is sometimes included as if it were merely an aspect of the keep-out role of song, we think that these are two qualitatively different, although complimentary, signal functions. Simple keep-out and social interaction signals have different complexity, meanings and targets. Keep-out signals are one-way signals broadcast to all receivers (known and unknown) as a marker of territory ownership, whereas social signals are directed at specific known individuals who often reply back and may involve repertoires of signals that transmit a variety of information.

From the social communication perspective, territorial song interactions can be thought of as an ongoing game of strategy, with players continually adjusting their signals to indicate different states of aggressive motivation, in response to the current circumstances. For example, bird A may approach a contested spot at the common territory boundary, eliciting an escalatory signal of immediate threat from the neighbor, bird B, which indicates B's intention to attack and defend that particular spot if A persists. Bird A perceives B's threat, but does not value the disputed area enough to escalate, so retreats further inside his territory and sings a deescalation signal, indicating his unwillingness to defend the space he had occupied. Later on, bird A's mate may position her nest inside the disputed area, greatly increasing its value to bird A and therefore his motivation to escalate and signal aggressively to bird B. In this simplified example, the differing value of a patch of territory is the variable that determines the neighbors' use of different signals. The overall aggressive motivation of the neighbors, and hence the signals they use, may fluctuate regularly and rapidly due to changes in breeding status, nest placement, distracting disputes with other neighbors, and numerous other social and ecological factors.

This type of communication game may be common among territorial animals that have frequent aggressive encounters with neighbors and for which there is fluctuation in either the value of the territory (or parts of the territory) or motivation to defend it (Bradbury \& Vehrencamp, 1998; Waas, 1990; Enquist et al., 1985). In these communication systems, the information carried by the signals is thought to be that of graded levels of aggressive motivation, which is the most useful information for deciding which opponent is more likely to win a fight. The number of different motivation signals needed in such a communication system likely depends on the importance of transmitting precise levels of motivation. For example, if the cost of aggression is high and the value of defending territories fluctuates widely (as might be the case with closely packed asynchronous breeding territories), then many different signals may be required to indicate each participants' level of motivation with an adequate range and resolution so as to avoid costly fighting. As we discuss below, one of the major challenges for territorial songbirds is developing and maintaining a sufficient repertoire of signals to serve their communication needs. Note also that a signal repertoire is not the same thing as a song type repertoire. In addition to the song types it sings, a bird's complete signal repertoire includes all of its non-song vocalizations, visual signals, and, finally, the various signals that can be generated by the timing of their singing and choice of songs.

Songbirds apply their songs in various different ways to create the signal repertoires needed for territorial communication. Some species use timing of singing and patterns of song type switching relative to their opponent as a signal (for a good review of timing-based signals, see Todt \& Naguib, 2000). Black-capped chickadees can vary the pitch of their fee-bee songs and use this ability in conjunction with overlapping to signal dominance (Otter et al., 2002). Another class of signals is possible between neighbors who share some similar song types. By selecting which song type to sing in relation to what their neighbor is singing, birds can potentially send several different directed signals. We describe below how song sparrows, Melospiza melodia, use their shared and unshared songs in a graded communication system.

\section{Song sparrows as a model system for interactive communication}

\section{Background}

Song sparrows are an excellent species for studying the social interaction function of song, as well as the challenges birds face maintaining an adequate signal repertoire. Song sparrows have moderate sized song repertoires of about 9 song types (Peters et al., 2000), and use their songs most often to counter-sing with neighbors. The species is highly territorial during the breeding season (and throughout the year in non-migratory populations), and males have been shown to use an extensive diversity of acoustic and visual signals (Nice, 1943). We carry out our research on a sedentary (nonmigratory) population of song sparrows in an undeveloped 540-acre park that borders Puget Sound in Seattle, Washington. Typically 100-150 song sparrow males are on territories in our study population in a given year. Song sparrows in our population usually maintain the same territory for life; sometimes they make small moves, but rarely do they move more than one or two territories away from their original territory. The birds live in small neighborhoods in territorial mated pairs. These neighborhoods are mixtures of longtime neighbors and first-year birds. Young birds generally establish their territories sometime between their first year (following dispersal from the birth area) and the following spring. 

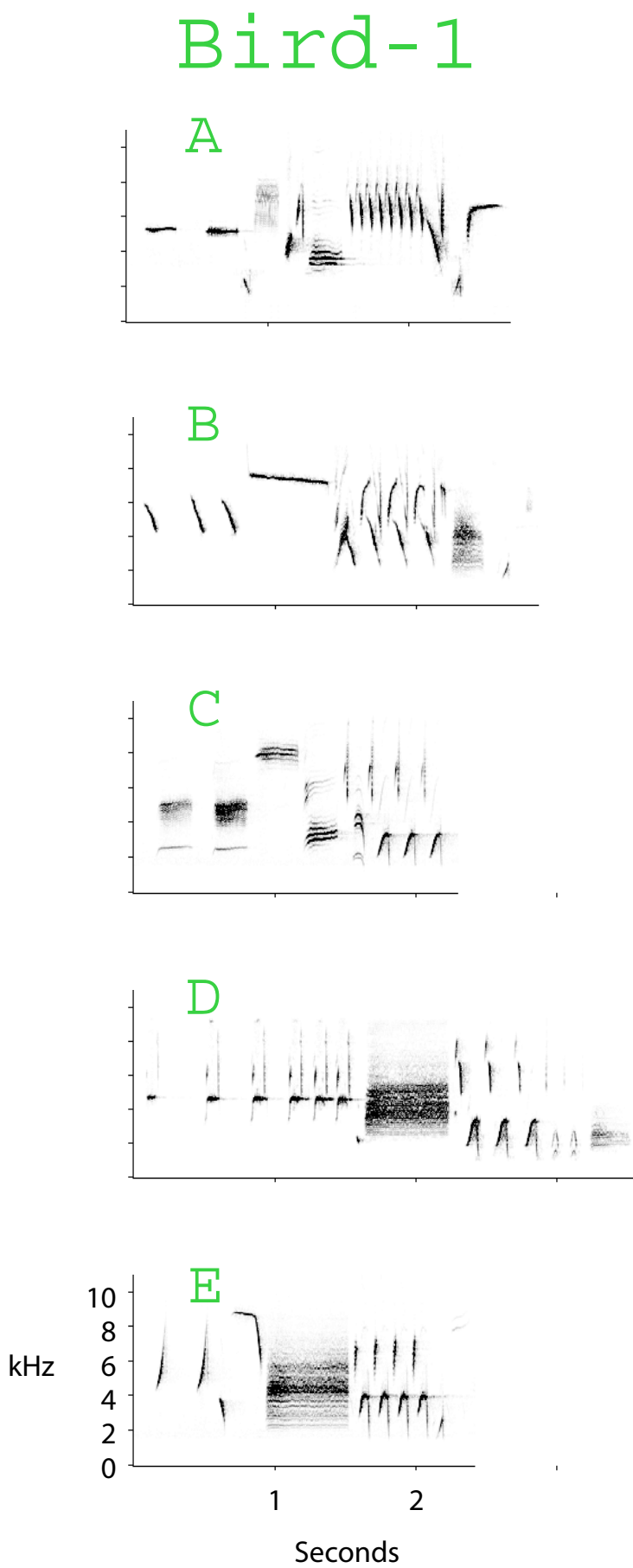

Bird-2
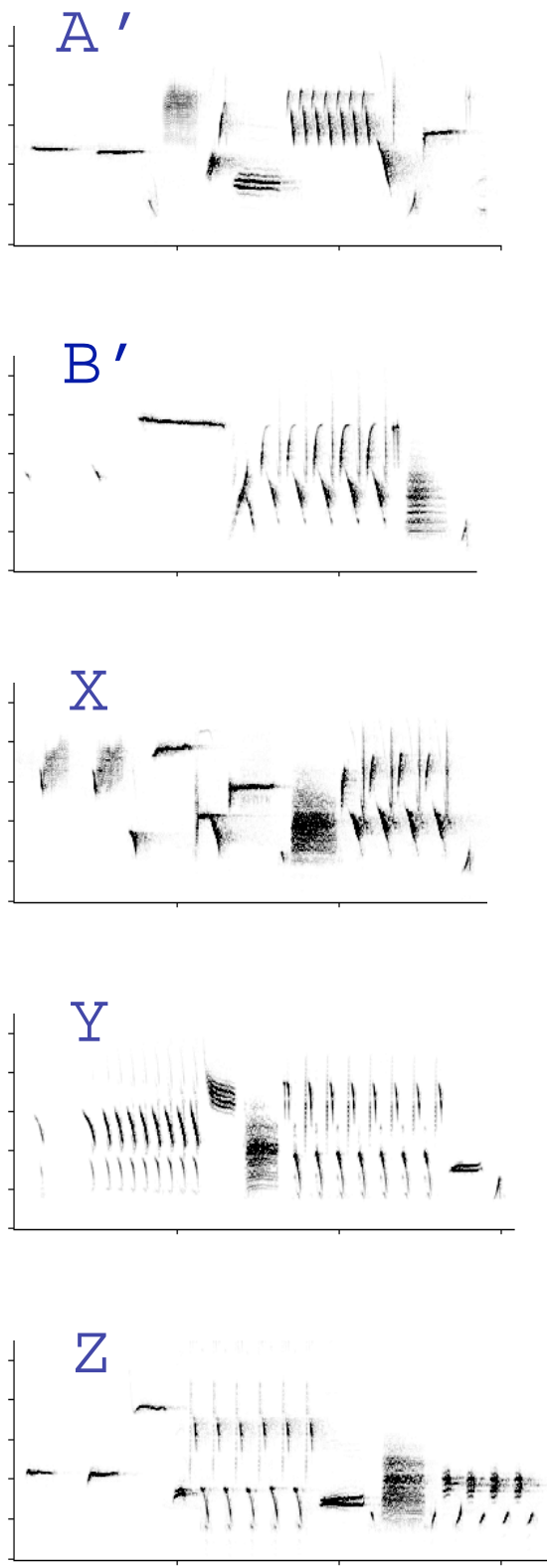

Figure 1. Hypothetical partial song type repertoires of Bird-1 and Bird-2. These birds share two common song types: A and $A$ ', and B and B'. Some of their unshared types may be matched on the basis of broad-sense similarity: $C$ and $X$ both start with two buzz notes, while D and Y both start with a long trill that increases in tempo, which we call a 'speed-up' trill. The remaining pair of song types ( $E$ and $Z$ ) are not similar to any song in the other bird's repertoire. In our Seattle song sparrow population, the remaining 3-5 song types in each bird's repertoire, not shown here, are likely to be unshared types.

The song types in a song sparrow's repertoire are copied from a number of other birds in the song-learning phase and do not have an individually distinctive vocal signature (Beecher et al., 1994), which means that to recognize his neighbors, a bird must memorize all of their individual songs (Stoddard et al., 1992b). A song sparrow sings his songs with 'eventual' variety; he repeats a particular song type a number of times before switching to a new song type. Under conditions of non-interactive free singing, birds tend to avoid repeating recently sung types, so that they cycle through their repertoire. In addition to the very large differences between song types, song sparrows also make small changes in suc- 
cessive renditions of a song type (e.g. changing the number of repeated elements in trills, changing the duration of buzzes, or adding or dropping notes to the end of the song). Variation in a song type, however, is small compared with variation among songs, and song types are clearly defined by the eventual-variety style of singing (Stoddard et al., 1988; Podos et al., 1992; Nowicki et al., 1994).

In our population, and in other sedentary populations studied, two adjacent males in a neighborhood generally 'share' some songs, i.e., have songs that are very similar structurally (songs A and A', and B and B' in Figure 1 are examples of a song type shared between two neighbors). The pattern of neighbor song type sharing arises because young birds learn the songs of the neighborhood they enter in their first year and in which they remain for the rest of their lives (Beecher et al., 1994b; Nordby et al., 1999). Although the number of songs shared between two neighbors varies from 0 to $100 \%$, the average percentage of shared songs in our study population is currently about $30 \%$. Song sparrows do not modify their song repertoire after their first breeding season (Nordby et al., 2002), but young birds moving into the area each year learn the songs of the older birds there and thus song sharing is maintained in the neighborhood via cultural transmission.

\section{Using Song Repertoires in Counter-Singing Interactions}

The fact that two neighbors share some but not all of their songs gives them a mechanism for a graded interaction system. A bird can reply to his neighbor in several different ways: with a song match or type match (the same song type his neighbor has just sung), with a repertoire match (a song shared with but not recently sung by his neighbor), or an unshared song type (Beecher et al., 1996). For example, if Bird-1 in Figure 1 sings type A, then Bird-2 could type match him by singing A', repertoire match by singing B', or sing unshared type $\mathrm{Z}$.

Many studies have shown that in such populations, birds will, at least under some circumstances, type match, i.e., reply to a shared song with the same song type (e.g., Lemon, 1968; Krebs et al., 1981; Falls, 1985). Most workers have viewed type matching as a way of directing your response at the bird who has just sung. The idea that it is advantageous to be capable of replying to a bird with the same song type has been around for some time (see Bremond, 1968; Krebs et al., 1981; Smith, 1991) and the more specific idea that type matching is a threat was first clearly articulated by Krebs et al. (1981). Their study and others (Falls et al., 1982; Falls, 1985), have provided mixed support for the threat hypothesis.

One finding that at first was difficult to reconcile with the threat hypothesis was that lower rates of type matching were elicited when the stimulus song was a shared neighbor song than when it was the bird's own song or a song of a stranger that was similar to one of the bird's own songs (Falls et al., 1982; McArthur, 1986; Stoddard et al., 1992). Song sparrows, for example, match neighbor song only at about chance $(\sim 10 \%)$ level (Stoddard et al., 1992). We were able to shed some light on this finding in a study of established song sparrow neighbors, tested mid to late in the breeding season. While these birds, as expected, did not type match the broadcast neighbor song, they did consistently reply with some other song they shared with that neighbor (Beecher et al., 1996). As noted above, we have dubbed this pattern of song selection 'repertoire matching'.

In another experiment, we tested response to neighbor song by new neighbors twice during the breeding season: early, in April, and again a month and a half later (Beecher et al., 2000a). Early in the breeding season, new neighbors will have only recently established their territorial boundary, which may still be in dispute, and territorial skirmishes will have occurred recently or may still be occurring. A new neighbor singing at the boundary early in the season represents a more serious challenge than a well-established neighbor singing at that same boundary. As predicted, we found that early in the season birds usually replied to a shared neighbor song with a type match, whereas a month and a half later they usually replied with a repertoire match. These results suggest that type matching is a more aggressive or escalated response than is repertoire matching. But though type matching may be a threat, we found no correlation between type matching and measures of aggression such as number of flights, closest approach to the speaker, and number of visual threat displays. This suggests that although type matching may be a threat, it is more a signal of aggressive motivation than it is a component of actual aggression. It may seem counter-intuitive that a threat signal is not backed up by immediate aggressive action by the signaler, however this does make sense from the social signaling perspective. In the heirarchy of escalation and de-escalation signals that a species uses, an escalatory signal such as a type match may by one or more steps removed from the physical aggression stage in the interaction. Put another way, a bird may type match a neighbor to indicate that he is motivated to stand his ground and fight if the interaction escalates further. The onus is then placed on the neighbor who received the type match to either de-escalate or escalate (which might then include approach and physical confrontation).

A subsequent playback study provided support for the idea that, although type matching is not immediately associated with aggressive response, it is nevertheless treated as a threat by neighbors. In Burt et al (2001) we showed that song sparrows regard being type matched as a threat and that being repertoire matched is less so. In this experiment, we used interactive playback to simulate a neighbor in an adjoining 


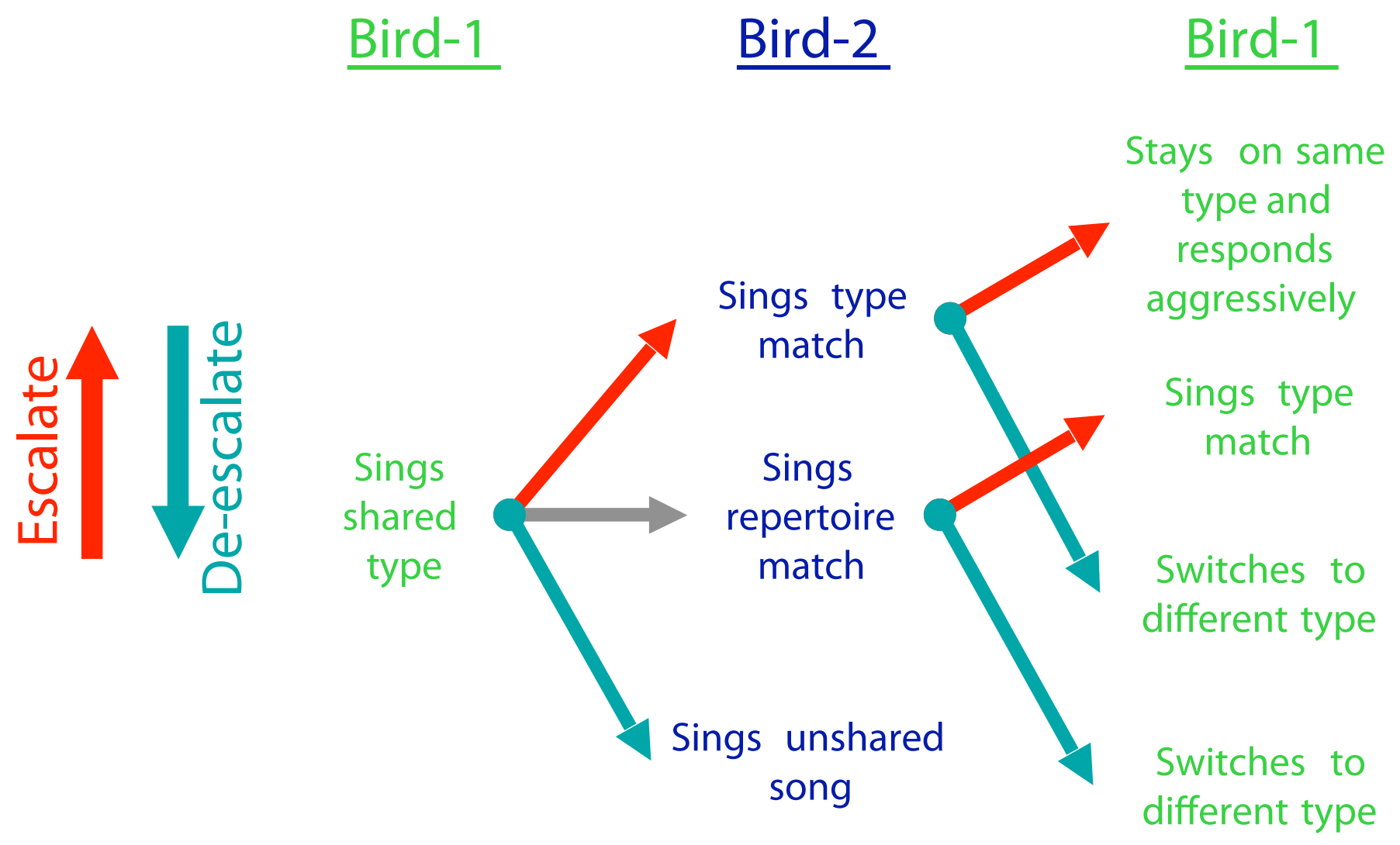

Figure 2. Signaling rules used by song sparrows during neighbor interactions. Birds can escalate (red arrows), maintain the same level (gray arrow), or de-escalate (cyan arrow). At higher levels of escalation, song signals give way to approach, visual displays, soft song, and eventually fighting. At the lowest levels of de-escalation (e.g., a switch to an unshared type) the opponents may stop interacting altogether.

territory issuing a song reply to a singing subject. When the subject sang a song shared with a neighbor, we simulated the neighbor issuing a song reply, either a type match or, on a different day, a repertoire match. Song sparrows responded to the neighbor song playback more aggressively when it was a type match than when it was a repertoire match, supporting the prediction that birds on their own territory will perceive a type match from a neighbor as a challenge and will be more likely to escalate. Moreover, some subjects responded more strongly than others when type-matched, and those who did continued to sing the matching type throughout the trial, whereas those who responded more weakly either switched types or stopped singing. Thus replying to your neighbor by continuing to sing the same song type is both a signal of and a predictor of aggressive response.

In a follow-up study (Beecher \& Campbell, 2005), we used playback experiments to examine how neighbors use their unshared songs. We tested and confirmed two predictions: (1) that a bird would be more likely to perceive a neighbor's song as directed at him if it was shared than if it was unshared; (2) that an unshared song would be a more effective de-escalation signal than a shared song. In the first of two playback experiments, subjects responded with shorter latencies to neighbors' shared songs than to their unshared songs. In the second, 'interactive' playback experiment, a playback trial began when the subject sang a shared song type. We replied with the neighbor's matching type (an escalation signal), until the subject approached, and then switched to either a different shared song (a 'repertoire match') or to an unshared song. As predicted, subjects responded less aggressively and departed sooner when the switch was to an unshared song than when it was to a shared song.

We summarize these studies with the 'singing rules' they seem to indicate for our western population of song sparrows. These rules are summarized in Figure 2. Neighbors use song signals in the initial or low-aggression stages of an escalated encounter. Repertoire matching appears to be used as a low aggression signal directed to a specific other neighbor. To escalate (i.e., indicate a higher level of aggressive motivation) the bird type matches the neighbor. A bird who is type matched can escalate by continuing to sing the same type, or de-escalate by switching to a different type. At this 
stage, if the opponents have not resolved their situation, then they will approach, give visual displays, sing quietly at close range (soft song), and eventually fight (Searcy et al., 2006).

Type matching is a particularly important escalation signal to song sparrows because it is the first of a series of aggressive escalation signals. Without the ability to type match, a bird could pay the costs of longer and more escalated counter-singing interactions because his opponent may misunderstand his aggressive motivation (i.e., make assessment errors), as well as suffer the increased likelihood of injury-causing fights. A more indirect cost arising from the inability to match opponents may come from eavesdropping by other individuals (mates, neighbors, floaters looking for a territory). In support of this hypothesis, we have found that song sparrows who share songs with neighbors tend to have longer territory tenure than low-sharing birds (Beecher et al., 2000b; and see also Wilson et al., 2000). In another western song sparrow population, birds with low neighbor song sharing fought more and were less likely to defend their territory throughout the season (Wilson \& Vehrencamp, 2001).

\section{What do birds do when they can't type match?}

As suggested earlier, in order to signal to all neighbors with type and repertoire matches, a bird must first have a song repertoire that includes at least some types shared with each neighbor. In many cases, however, a bird may have acquired a less than optimal repertoire and will not share with all (or perhaps any) neighbors, or may share so few song types that he can rarely type match his neighbors. This dilemma could occur if a bird memorizes the songs of nonneighbors in a different location, or because some neighbors are newly arrived from elsewhere and it was not possible to learn their songs. Birds in migratory populations may present a particular problem for acquiring neighbor-shared songs since they may have been unable to return and establish territories near enough to where they learned their songs. Regardless of the reason, a bird is likely to be faced with at least some neighbors with whom he shares very few or no common song types. Also, even if a male shares songs with each of his neighbors he may still be unable to match a neighbor during a given counter-singing bout if the neighbor isn't singing a shared type. This is likely to happen when neighbors share relatively few song types and if singers are reluctant to repeat recently sung types (as is the case with song sparrows). In that case singers cannot reasonably sing only (type matchable) repertoire matches during a long bout of counter-singing.

The importance of type matching as a signal has been questioned, since in some populations, individuals do not share song types with neighbors, and therefore cannot type match (Hughes et al., 1998). We suggest two hypothetical alternative strategies that birds (song sparrows and other repertoire species) might pursue to solve this problem, similarity matching and conventional matching.

\section{Similarity matching as an alternative to type matching}

Neighbors who share no songs could still song match by replying to one another's song types with their most similar song types. That is, if they cannot type match in the strict sense, they can instead use less-strict matching criteria. We tested the hypothesis that a bird lacking a true type match could still song match a stimulus song with a similar song from his repertoire. In a pair of playback experiments (Burt et al., 2002), we presented the subject with a stranger song that was similar to one or more of his songs, but a type match to none of them. In the first experiment, we used playback songs that began with two buzzes ('double-buzz' songs, e.g., types $\mathrm{C}$ and $\mathrm{X}$ in Figure 1). In the second experiment, we used songs that began with a slow trill that increased in tempo ('speed-up' songs, e.g., types D and Y in Figure 1). Birds replied at rates significantly above chance with their own double-buzz, or speed-up song match to the respective types of playback. This broad-sense form of song matching may substitute for type matching and repertoire matching in populations with low song type sharing, or in populations such as ours where particular neighbors may not share song types. Similarly,in a low-sharing eastern U.S. song sparrow population, Anderson et al (2005) showed that birds match with songs that share only some common elements, but are not similar enough otherwise to pass either their or our criterion for 'shared songs'. Similarity matching has been demonstrated in other species as well. For example, nightingales will match playback of whistle songs with a song type that may be structurally dissimilar, but which has a whistle pitch close to or slightly higher than the playback type (Naguib et al., 2002).

Thus, by loosening their matching criteria to include songs that are merely similar in some way, a bird might still be able to match an opponent with whom he shares no song types. It could even be the case that 'type matching' and 'similarity matching' are both based on a single more basic cognitive strategy: 'sing my most similar song type to the opponent's song type'. Type matching may be just the most obvious and unambiguous similarity matching category, and therefore the one that birds should use first, if possible. By this rule, a bird should type match if he can, but if he can't type match then he should sing the most similar song he has in his repertoire. However, as the similarity between a match and its target decreases, ambiguity and the chance that the signal will not be detected by the receiver will increase. At some point a pure similarity matching rule will break down - that is, a bird will have no particular song type reply to his neighbor's song type that is a similar enough to be perceived as a 'match'. 
Thus, in general birds may have a hierarchy of preference in favor of type matching, followed by less perfect matches, and then there may be neighbor songs that simply cannot be matched up with any type in the bird's repertoire on the basis of similarity. Figure 1 illustrates this range of potential similarity choices using a subset of the repertoires of a pair of neighboring song sparrows.

The 'most similar' matching strategy assumes that knowledge of the matching rule is known by all signalers and receivers, a reasonable assumption because categorizing by similarity is a natural and common cognitive function that occurs across sensory domains. For example, in operant studies, song sparrows categorize songs by type, lumping the same type sung by different singers into the same category (Horning et al., 1993; Beecher et al., 1994). To date, the question of whether type matching is a learned behavior has not been examined. It is possible that type matching is a culturally transmitted rule, having arisen in sharing populations as a natural consequence of the tendency to categorize by acoustic similarity. Once matching is established as an important signal in the population, then it may be generalized further as needed to include similarity matches of various kinds.

\section{Conventional matching as an alternative to type matching}

An even more difficult problem arises when a bird cannot match an opponent's song because it is below the similarity matching threshold with any of his own songs. In this case, by the 'best similarity' rule, the bird would have to wait until the opponent sings a song that is matchable by type or similarity (assuming he even has another song type that is matchable). In the Seattle song sparrow population, average song sharing with neighbors has fluctuated between $25 \%$ and $40 \%$, and several other song sparrow populations have been reported to have about $25 \%$ neighbor song type sharing (Hill et al., 1999; Wilson et al., 2000). With 25\% overall neighbor sharing in a population (or about 2 songs out of a 9 song repertoire), the scenario of a bird wanting to match a neighbor who is singing an unmatchable song is fairly likely.

We propose that birds who cannot match by similarity may use a different kind of matching rule as an alternative. One solution would be for opponents, and this would be most feasible for long-term neighbors, to establish specific pairings of unshared song types as 'matches'. These pairings need have no common structural similarity. That is, the pairings could be arbitrary and based on common agreement rather than common structure. We term this a conventional match because the pairing is based on an arbitrary convention between the two birds. For example, the birds in Figure 1 might designate the very dissimilar types $\mathrm{E}$ and $\mathrm{Z}$ as conventional matches; that is, when Bird-1 sings song type $E$ and receives $\mathrm{Z}$ as a reply, then he regards Bird-2 as having matched him. With this additional matching strategy, two birds who are familiar with one another might in theory be able to 'match' every song type in their neighbor's repertoire using a combination of type matches, similarity matches, and conventional matches.

As an aside, we should distinguish our term conventional match - the pairing of the song types of two birds by an arbitrary convention (as opposed to pairing by type or similarity) from Sandra Vehrencamp's related term 'conventional signal' - a signal for which the information content is defined by an arbitrary convention rather than by a cost or constraint inherent to the signal (Vehrencamp, 2000). For example, many frog calls are index (not conventional) signals of male condition because their fundamental frequency honestly indicates the frog's body size. In contrast, song selection signals such as type matches, repertoire matches, and conventional matches are conventional signals because the rules that allow a bird to associate a particular signal to a particular signal (e.g., "a type match means aggressive motivation") are defined purely by convention.

\section{Testing whether birds use conventional matches}

Unlike type, similarity, and repertoire matching, conventional matching would have to be based on an arbitrary agreement between the two neighbors. This agreement could be based on commonly understood rules, which would allow others to decipher the match, or it could be truly arbitrary and therefore unique and hidden from other listeners (including human observers). Special techniques are therefore necessary to detect whether two birds are engaging in conventional matching. To this end, we have tested whether birds are inclined to conventional match using captive song sparrows in the lab. Our current lab technique involves placing two birds into an isolated room and recording them over several days and many counter-singing interactions. The result of several recording sessions is (ideally) a record containing numerous counter-singing interactions in which each bird replies to the other. We then analyze whether a bird prefers to reply to the other's song types with specific songs from his own repertoire. For example, if a male tends to reply to his neighbor's song type $\mathrm{X}$ with his own song type $\mathrm{B}$, and we can detect little acoustical similarity between the two, then these are candidate songs for a conventional match pair. We can also test for reciprocity: does the neighbor prefer to reply with $\mathrm{X}$ to the subject's B type? Finally, we can experimentally test for conventional matching by isolating a bird and playing to him the neighbor's unshared, non-similar songs (e.g., the bird should reply with type B to playback of X).

The data analysis involves generating a matrix for each bird of how many times he replied with each one of his types 


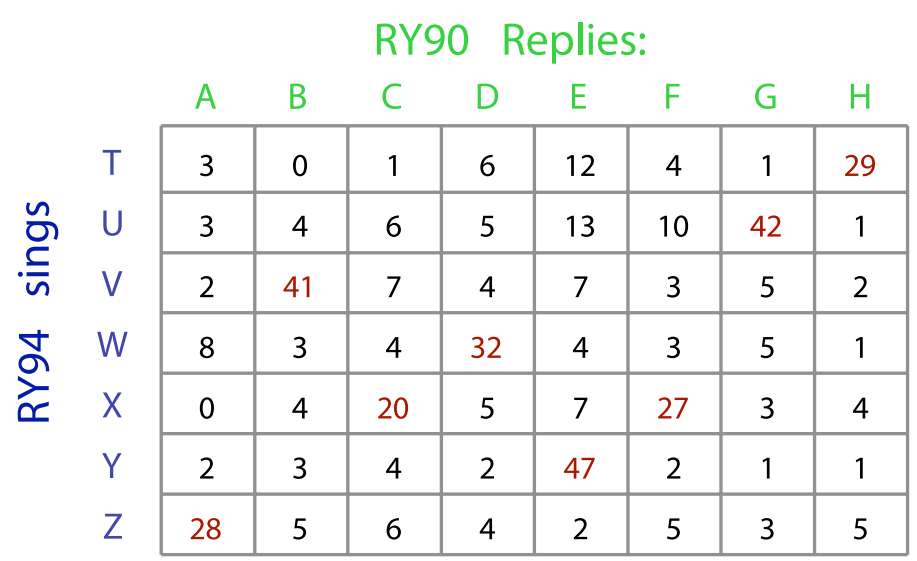

\section{RY94 Replies:}

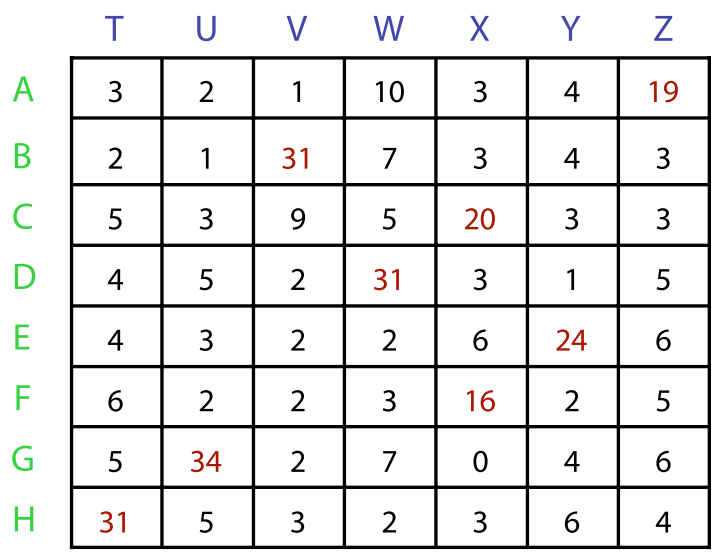

Table 1. Interaction matrices for subject song sparrow pair RY90 and RY94. Matrix numbers are counts of occurrences when one bird switch to reply to the other's particular type with his own particular type. This pair shared no song types, so if subjects had no tendency to conventional match, then there should have been equal counts for every reply type combination field. Instead, this pair showed a strong tendency to reply to each other with specific type pairings - demonstrating the existence of conventional matching (in this pair). This table was based on interactions recorded over 22 days, and a total of 10568 songs (7365 songs by RY90, and 3203 by RY94).

to each one of the other bird's types. We then compare the observed reply frequencies against the reply frequencies that would be expected if the birds had replied randomly with respect to each other. For this article, each significant reply preference reported (Table 1, Figures 3 and 4) was the result of a G-test of observed vs. expected reply counts for each type (e.g., each row in Tables 1). We have recorded and tested a number of pairs of song sparrow males using this method, and in several cases it is clear that the subject pairs who share no or few song types do use conventional matches in the same manner that other birds use type matches. Interestingly, however, the rate of conventional matching ob- served varies from pair to pair, a result which we will discuss below.

The pair of birds who have displayed conventional matching most clearly were two older captive song sparrows (RY90 and RY94), who share no song types and had interacted in our aviary for many years (Figure 3). This pair provided a nearly perfect demonstration of conventional matching, with each song type assigned as a reciprocal conventional match to one of the other bird's types. The one exception was also reasonable: RY90 had one more song type in his repertoire than RY94, so he replied to one of RY94's types (X) with two of his types (C and F), while RY94 sang $\mathrm{X}$ in response to RY90 C and F. The pair's reply preferences were remarkably consistent across the 22 day recording period, with the majority of replies being conventional matches (Table 1). We confirmed these results with playback experiments where one bird was removed and his songs presented by computer to the remaining bird; the next day we switched birds. The RY pair are perhaps a unique case, and their behavior and circumstances may have made them the most likely to show complete conventional matching. Both of these birds were more aggressive than any of our other captive sparrows, perhaps because they had been raised in the lab, had lived their many years as caged birds, and had never needed to back up their song threats with actual fighting. Thus they were the most likely to threaten their aviary 'neighbors' with type matches (our birds are housed nearby one another in separate cages). Furthermore, this now elderly pair have spent more time in each other's company than any of our other birds (10 years). Finally, the lack of any shared song types between them may have made them particularly keen to create conventional matches.

In addition to the RY90-RY94 pairing, we tested 8 pairs of much younger birds ( $\mathrm{N}=16$ subjects total, all two years old at the time of testing), some of whom shared several song types. The pairs with song sharing were interesting because their rate of type matching gave us an indication of their overall tendency to match, allowing us to sort out whether a bird who did not conventional match was not doing so because he did not use conventional matches as a signal, or because he simply was not inclined to match.

The younger pairs demonstrated a different pattern of response than the RY90-RY94 pair. Some birds showed no overall tendency to interact and match (type or conventional), while others type matched, and used some, but not all, of their unshared songs as conventional matches. Additionally, matches were not always reciprocal: one bird may have preferred to reply to his neighbor with a particular type, but his neighbor did not reciprocate. One pair, $\mathrm{CC}$ and HR, showed all of these trends, and we present them here as an illustration (Figure 4). 


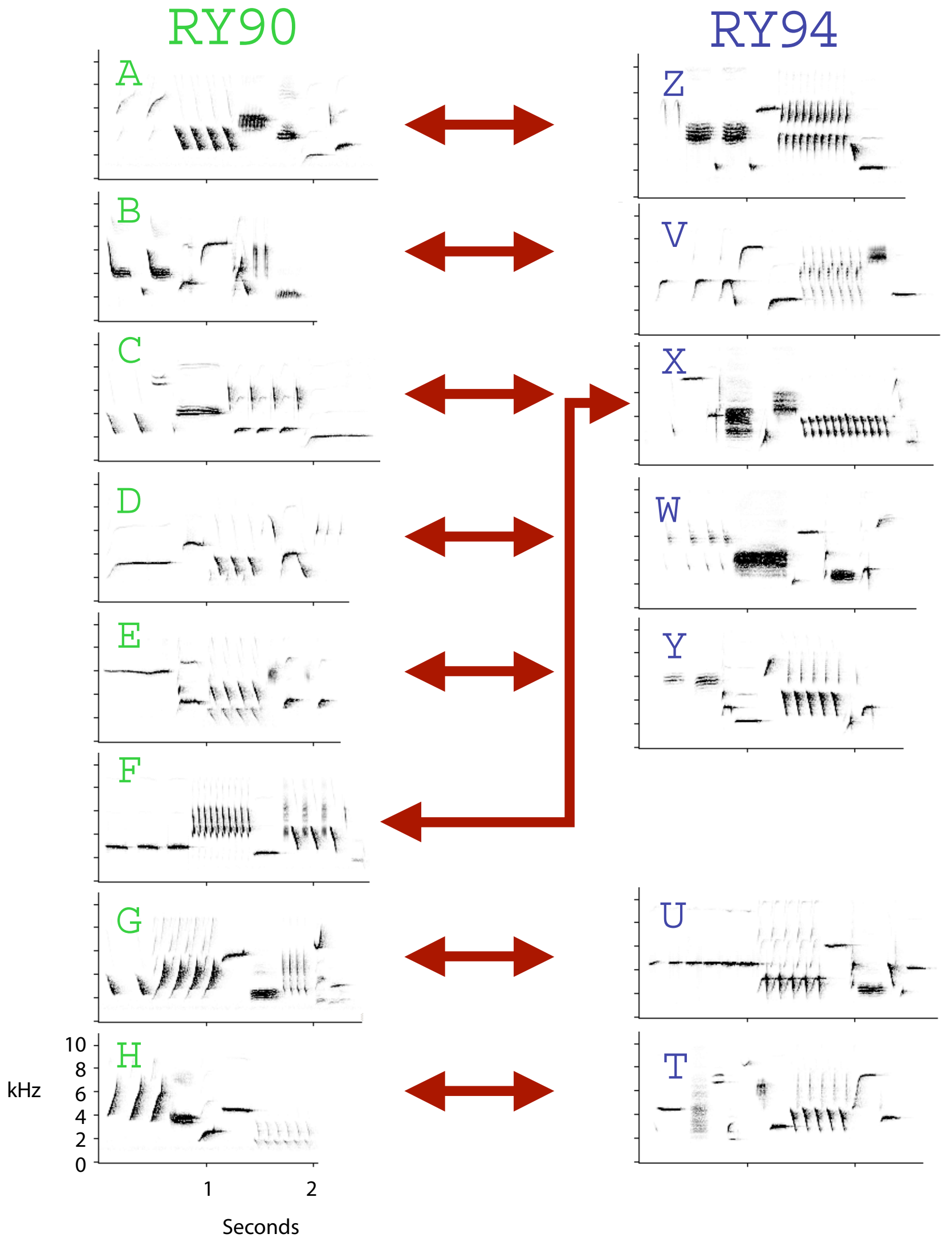

Figure 3. Song repertoires of song sparrows RY90 and RY94. When paired in a room next to each other and recorded, they showed a significant tendency to reply to one another with songs matched up by arrows $(G$-test $p<.05)$. Double arrow heads for all pairings indicate that each song type conventional match pairing was reciprocal (they replied to each other with the same type). RY90 had one more song type than RY94, and so he used his types $C$ and F to reply to RY94's type X. 

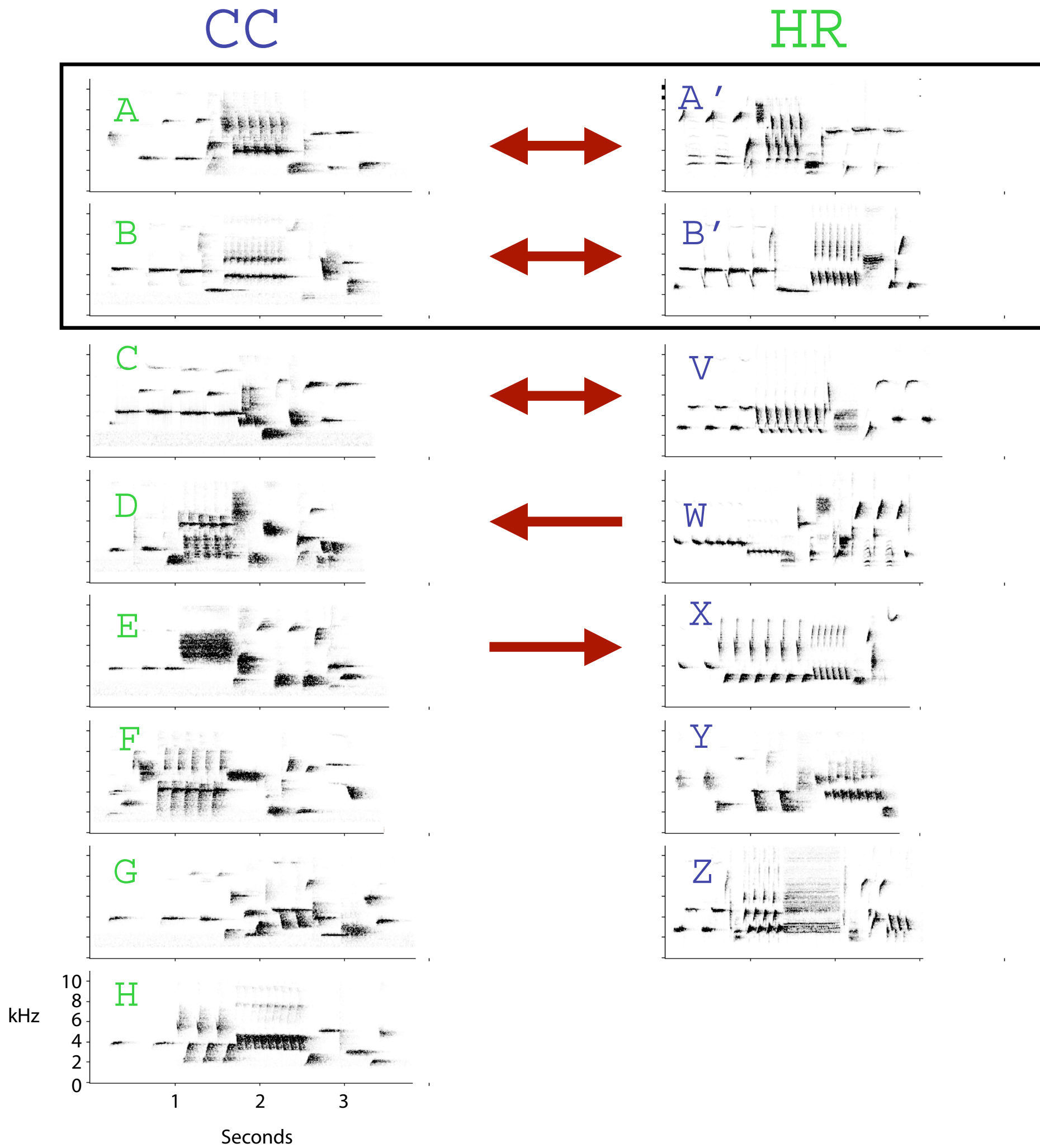

Figure 4. Song type reply preferences for subjects $C C$ and HR, two-year old birds who shared two song types (A and B). This pair used their shared types to type match. One pair of unshared types (CC-C and HR-V) had structurally similar beginning and ending notes and these types were used reciprocally as similarity matches. Two other unshared type pairs were non-reciprocal: only one bird preferred to reply to the other (HR-W to CC-D, and CC-E to HR-X). The remaining unshared types were not consistently used as replies to any specific song type. All arrows indicate significant reply preferences $(G$-test, $p<0.05$ ). 
The lower degree of conventional matching seen between younger pairs as compared to the older pair may have been the result of three non-exclusive processes. First, the younger birds had had much less time to interact with one another than RY90 and RY94 and thus may still have been in the process of establising their conventional match pairings. This is supported to some extent by an earlier pilot experiment in which we placed pairs of yearling song sparrows with low levels of type sharing into nearby aviaries and recorded them for their first adult spring and summer. The outcome was that the four pairs of birds we tested demonstrated some preferred unshared reply type pairings, but that the type pairings tended to be non-reciprocal and shifted and changed across the season, as if the neighbors had not yet agreed upon a permanent and reciprocal pairing of conventional match types. It is possible that in the wild, neighbors may take some time, perhaps more than one year, to decide which of their unshared song types to pair up as conventional matches. If territorial birds in nature use conventional matches (and to be clear: conventional matching has not yet been observed in the wild), then the process of negotiating with each neighbor long enough to establish conventional match pairings represents a potentially significant social investment. The benefits of conventional matching and the time investment it may take to develop the signals may be one of the factors behind the widely documented 'Dear Enemy' phenomenon in which neighbors show lower aggression towards each other than towards strangers (Fisher, 1954; Getty, 1987; Temeles, 1994).

Another possible explanation for the difference between the old and young lab subjects is that the younger birds were less inclined to match their 'neighbors' because they were less inherently aggressive. The young birds did appear to be less aggressive (as measured by observations of threat displays, and the lower tendency to type match) compared to the two older birds, who were always highly aggressive (they had been used for years as netting decoys in the field for this reason). We intend to examine this idea with some of the young pairs by giving them testosterone implants to increase their aggressive motivation and re-test them in the spring.

As noted, because of their circumstances and aggressive behavior, RY90 and RY94 may have been an extreme case of conventional matching. In which case, the young birds were perhaps using a more natural matching strategy. It could be that, rather than assigning all of their unshared songs as conventional matches as RY90 and RY94 did, it may be more natural to only select a few to use for this purpose. This strategy might make sense if neighbors only need to have a few shared song types or conventional matches to communicate efficiently (notwithstanding the occasional inability to type match their opponent). If true, then we might predict that neighbors in the wild with not enough (or no) shared types will only negotiate a few conventional match unshared song pairings to fill out their complement of type or similarity matchable songs.

The lab experiments we have presented demonstrate that song sparrows are capable of spontaneously using unshared song types as conventional matches. The lab studies do not, however, prove that birds in natural populations are actually using conventional matching, and if they are, to what degree and what for. We therefore still consider the concept of conventional matching to be a tentative hypothesis, backed up by some compelling evidence. Carefully designed field studies will be needed to demonstrate the existence and functional use of conventional matching in natural populations. To that end, we are planning several field experiments to test the conventional matching hypothesis. In one experiment, we will use automated techniques similar to our lab methods to record wild song sparrow neighbor pairs. The pairs would be chosen in areas where territories are arranged in linear end-to-end territories (such as the bushes along a stream bed surrounded by open fields) so that we can more easily identify who each bird is communicating with (a nearly impossible task in two-dimensional territory arrangements). We can then analyze the natural singing interactions of wild subjects as we do with the lab birds to look for conventional match pairings of unshared song types. If putative conventional matches are found, then we can conduct interactive playback experiments to determine their signal function. Our hypothesis is that neighbors with low song type sharing should use conventional matching as a replacement for the escalatory signal of type matching. Therefore we would predict that subjects will respond with higher aggression when a conventional match is played to them, than when other songs are played.

\section{Summary and Conclusions}

In this paper we have focused on a particular function of song in territorial birds, the negotiation of territorial and other resource disputes through counter-singing. We have gathered considerable evidence to show that in western populations, two neighboring song sparrows will use the distinction between the songs they share (very similar song types) and the songs they do not share (dissimilar song types) as the basis for a graded communication system. The core of the communication system is a rule for escalating an interaction (type match the other bird) or de-escalating the interaction (sing an unshared song, or stop singing); repertoire matching, or singing a different shared song than your opponent has just sung, appears to be intermediate. The communication system we describe is primarily social - that is, song communication is interactive and designed to reduce aggression between neighbors. The social aspect of song commu- 
nication may explain the use of multiple signals, which are needed to adequately transmit the required range of motivation and other information. We suggest that the social role of bird song is complimentary to its keep-out role.

Two difficulties stand in the way of our generalizing this rule to other songbird species. First, about a quarter of all species have a single-song repertoires (Kroodsma, 1982). In some of these cases, however, a bird has the ability to vary the frequency of the song, and can match an opponent's song by frequency shifting appropriately (black-capped chickadees, Otter et al., 2002; kentucky warbler, Morton \& Young, 1986). Other single-song species may utilize alternative mechanisms such as temporal variations or song overlapping to mediate neighbor interactions. The second and more serious problem, however, is that in some species, including in fact some eastern populations of song sparrows, neighbors do not share song types, or at least share no more with neighbors than they do with more distant birds in the population. Moreover, even in song-sharing populations such as ours, it is not unusual to find some birds that share few songs, in some cases, no songs at all.

We have presented evidence that in these circumstances, a first resort appears to be used songs that are broadly similar in some respect. These song pairs do not pass our 'song sharing' criterion, but we can show in field playback experiments and lab operant conditioning experiments, that the birds regard these songs as similar. Yet such 'similarity matching' may fail in circumstances where two neighbors have no or few such similar pairs. We have suggested that in this circumstance, neighbors could resort to 'conventional matching', that is, they could agree as to which song in one bird's repertoire could be paired up. This is a difficult phenomenon to demonstrate in the field, and we have begun with laboratory experiments involving caged birds that have lived as 'neighbors' for varying periods. Our preliminary results have been encouraging, and we plan to take this problem into the field. We propose that type matching, similarity matching and conventional matching may all be points on a continuum of song matching. If two neighboring birds match up some fraction of their repertoires in this way, but not all of their songs, then they would still have the key distinction of paired songs with which they could song match or repertoire match. We hope to test this communication hypothesis in future field tests.

\section{References}

Anderson, R. C., Searcy, W. A. \& S., N. 2005. Partial matching in an eastern population of song sparrows, Melospiza melodia. Animal Behaviour, 69, 189-196. doi:10.1016/j.anbehav.2004.02.019

Beecher, M. D. \& Campbell, S. E. 2005. The role of unshared songs in singing interactions between neighbouring song sparrows. Animal Behaviour, 70, 1297-1304. doi:10.1016/j.anbehav.2005.03.008

Beecher, M. D., Campbell, S. E. \& Burt, J. M. 1994. Song perception in the song sparrow: birds classify by song type but not by singer. Animal Behaviour, 47, 1343-1351.

doi:10.1006/anbe.1994.1182

Beecher, M. D., Campbell, S. E., Burt, J. M., Hill, C. E. \& Nordby, J. C. 2000a. Song type matching between neighbouring song sparrows. Animal Behaviour, 59, 21-27. doi:10.1006/ anbe.1999.1276

Beecher, M. D., Campbell, S. E. \& Nordby, J. C. 2000 b. Territory tenure in song sparrows is related to song sharing with neighbours, but not to repertoire size. Animal Behaviour, 59, 29-37. doi:10.1006/anbe.1999.1304

Beecher, M. D., Stoddard, P. K., Campbell, S. E. \& Horning, C. L. 1996. Repertoire matching between neighbouring song sparrows. Animal Behaviour, 51, 917-923.

doi:10.1006/anbe.1996.0095

Bradbury, J.-W. \& Vehrencamp, S.-L. 1998. Principles of animal communication. Sunderland, Massachusetts.: Sinauer Associates, Inc.

Bremond, J. C. 1968. Recherches sur la semantique et les elements vecteurs d'information dans les signaux acoustiques du rouge-gorge (Erithacus rubecula L.). Terre Vie, 2, 109220.

Burt, J. M., Bard, S. C., Campbell, S. E. \& Beecher, M. D. 2002. Alternative forms of song matching in song sparrows. Animal Behaviour, 63, 1143-1151. doi:10.1006/anbe.2002.3011

Burt, J. M., Campbell, S. E. \& Beecher, M. D. 2001. Song type matching as threat: A test using interactive playback. Animal Behaviour, 62, 1163-1170. doi:10.1006/anbe.2001.1847

Catchpole, C. K. \& Slater, P. J. B. 1995. Bird song: biological themes and variations. New York: Cambridge University Press.

Enquist, M., Plane, E. \& Röed, J. 1985. Aggressive communication in fulmars (Fulmarus glacialis) competing for food. Animal Behaviour, 33, 1007-1020. doi:10.1016/S0003-3472(85)80035-X

Falls, J. B. 1985. Song matching in western meadowlarks. Canadian Journal of Zoology, 63, 2520-2524. doi:10.1139/z85-373

Falls, J. B., Krebs, J. R. \& McGregor, P. 1982. Song matching in the great tit (Parus major): The effect of similarity and familiarity. Animal Behaviour, 30, 997-1009. doi:10.1016/S0003-3472(82)80188-7

Fisher, J. B. 1954. Evolution and bird sociality. In: Evolution as process (Ed. by Huxley, J., Hardy, A. C. \& Ford, E. B.), pp. 71-83. London: Allen \& Unwin.

Getty, T. 1987. Dear enemies and the prisoner's dilemma: why should territorial neighbors form defensive coalitions? Amer. Zool., 27, 327-336.

Hill, C. E., Campbell, S. E., Nordby, J. C., Burt, J. M. \& Beecher, M. D. 1999. Song sharing in two populations of song sparrows. Behavioral Ecology \& Sociobiology, 46, 341-349. doi:10.1007/s002650050628

Horning, C. L., Beecher, M. D., Stoddard, P. K. \& Campbell, S. E. 1993. Song perception in the song sparrow: importance 
of different parts of the song in song type classification. Ethology, 94, 46-58.

Hughes, M., Nowicki, S., Searcy, W. A. \& Peters, S. 1998. Song-type sharing in song sparrows: implications for repertoire function and song learning. Behavioral Ecology and Sociobiology, 42, 437-446. doi:10.1007/s002650050458

Krebs, J. R., Ashcroft, R. \& Van Orsdol, K. 1981. Song matching in the great tit Parus major L. Animal Behaviour, 29, 918923. doi:10.1016/S0003-3472(81)80029-2

Kroodsma, D. E. 1982. Song repertoires: problems in their definition and use. In: Acoustic Communication in Birds (Ed. by Kroodsma, D. E. \& Miller, E. H.), pp. 125-146. New York: Academic Press.

Kunc, H. P., Amrhein, V. \& Naguib, M. 2006. Vocal interactions in nightingales, Luscinia megarhynchos: more aggressive males have higher pairing success. Animal Behaviour, 72, 25-30.

doi:10.1016/j.anbehav.2005.08.014

Lemon, R. E. 1968. The displays and call notes of cardinals. Canadian Journal of Zoology, 46, 141-151.

doi:10.1139/z68-023

McArthur, P. D. 1986. Similarity of playback songs to self song as a determinant of response strength in song sparrows (Melospiza melodia ). Animal Behaviour, 34, 199-207. doi:10.1016/0003-3472(86)90024-2

McDonald, M. V. 1989. Function of song in Scott's seaside sparrow, Ammodramus maritimus peninsulae. Animal Behaviour, 38, 4668-485.

doi:10.1016/S0003-3472(89)80040-5

Mennill, D. J. \& Ratcliffe, L. M. 2004. Overlapping and matching in the song contests of black-capped chickadees. Animal Behaviour, 67, 441-450.

doi:10.1016/j.anbehav.2003.04.010

Mennill, D. J., Ratcliffe, L. M. \& Boag, P. T. 2002. Female eavesdropping on male song contests in songbirds. Science, 296, 873. doi: $10.1126 /$ science. 296.5569 .873

Morton, E. S. \& Young, K. 1986. A previously undescribed method of song matching in a species with a single song "type," the Kentucky warbler (Oporornis formosus). Ethology, 73, 334-342.

Naguib, M., Mundry, R., Hultsch, H. \& Todt, D. 2002. Responses to playback of whistle songs and normal songs in male nightingales: Effects of song category, whistle pitch, and distance. Behavioral Ecology \& Sociobiology, 52, 216223. doi:10.1007/s00265-002-0511-1

Naguib, M. \& Todt, D. 1997. Effects of dyadic vocal interactions on other conspecific receivers in nightingales. Animal Behaviour, 54, 1535-1543. doi:10.1006/anbe.1997.9997

Nice, M. M. 1943. Studies in the life history of the song sparrow II. The behavior of the song sparrow and other passerines. Transactions of the Linnean Society of New York, 6, 1-328.

Nordby, J. C., Campbell, S. E. \& Beecher, M. D. 2002. Adult song sparrows do not alter their song repertoires. Ethology, 108, 39-50. doi:10.1046/j.1439-0310.2002.00752.x

Nowicki, S., Searcy, W. A. \& Hughes, M. 1998. The territory defense function of song in song sparrows: A test with the speaker occupation design. Behaviour, 135, 615-628.

Otter, K., McGregor, P., K., Terry, A., M. R., Burford, F., R. L., Peake, T., M. \& Dabelsteen, T. 1999. Do female great tits (Parus major) assess males by eavesdropping? A field study using interactive song playback. Proceedings of the Royal Society of London. Series B: Biological Sciences, 266, 13051309. doi:10.1046/j.1439-0310.2002.00764.x

Otter, K. A., Ratcliffe, L., Njegovan, M. \& Fotheringham, J. 2002. Importance of frequency and temporal song matching in black-capped chickadees: Evidence from interactive playback. Ethology, 108, 181-191.

Peake, T. M., Matessi, G., McGregor, P. K. \& Dabelsteen, T. 2005. Song type matching, song type switching and eavesdropping in male great tits. Animal Behaviour, 69, 1063-1068. doi:10.1016/j.anbehav.2004.08.009

Peters, S., Searcy, W. A., Beecher, M. D. \& Nowicki, S. 2000. Geographic variation in the organization of song sparrow repertoires. Auk, 117, 936-942. doi:10.1642/0004-8038(2000)117[0936:GVITOO]2.0.CO;2

Searcy, W. A., Anderson, R. C. \& Nowicki, S. 2006. Bird song as a signal of aggressive intent. Behavioral Ecology and Sociobiology, 60, 234-241. doi:10.1007/s00265-006-0161-9

Smith, W. J. 1991. Singing is based on two markedly different kinds of signaling. J. Theor. Biol., 152, 241-253. doi:10.1016/S0022-5193(05)80455-2

Stoddard, P. K., Beecher, M. D., Campbell, S. E. \& Horning, C. L. 1992. Song-type matching in the song sparrow. Canadian Journal of Zoology, 70, 1440-1444. doi:10.1139/z92-200

Temeles, E. 1994. The role of neighbours in territorial systems: when are they 'dear enemies'? Animal Behaviour, 47, 339350. doi:10.1006/anbe.1994.1047

Todt, D. \& Naguib, M. 2000. Vocal interactions in birds: The use of song as a model in communication. In: Advances in the study of behavior (Ed. by Slater, P. J. B. \& Rosenblatt, J. S.), pp. 247-296. San DiegO: Academic Press.

Vehrencamp, S. L. 2000. Handicap, index, and conventional signal elements of bird song. In: Animal Signals: Signalling and Signal Design in Animal Communication (Ed. by Espmark, Y., Amundsen, T. \& Rosenqvist, G.), pp. 277-300. Trondheim, Norway: Tapir Academic Press.

Waas, J. R. 1990. Intraspecific variation in social repertoires evidence from cave-dwelling and burrow-dwelling little blue penguins. Behaviour, 115 63-99. doi:10.1163/156853990X00293

Wilson, P. L., Towner, M. C. \& Vehrencamp, S. L. 2000. Survival and song-type sharing in a sedentary subspecies of the Song Sparrow. Condor, 102, 355-363. doi:10.1650/0010-5422(2000)102[0355:SASTSI]2.0.CO;2

Wilson, P. L. \& Vehrencamp, S. L. 2001. A test of the deceptive mimicry hypothesis in song-sharing song sparrows. Animal Behaviour, 62, 1197-1205. doi:10.1006/anbe.2001.1863 